\title{
Comments
}

\section{Rethinking Fairness: Perspectives on the Litigation Process}

\author{
Jon O. Newman†
}

\section{INTRODUCTION}

For decades critics of the litigation system have bemoaned the delays and costs of courtroom encounters while working mightily to refine the system in ways that make it even slower and more expensive. This paradoxical approach reflects the strengths and weaknesses of legal training. Skillful in analysis and advocacy, lawyers have recognized those aspects of trial procedure that can be changed to increase the likelihood of achieving better results and then engrafted well-intentioned changes onto an already complex system. At the same time, lawyers' preoccupation with results and their inadequate appreciation of the need to evaluate the system in which they function cause them to ignore the adverse consequences of the litigation process they have constructed. They know that the system is slow and costly. But they fail to recognize that the solutions they have developed over the years are a large part of the problem.

The paradox will continue until we realize that constructive change requires not simply adjustments in what we do in the courtroom but fundamental rethinking about what we are trying to accomplish there. In my judgment such rethinking should begin with the concept that underlies so much of our procedural and substantive law - the concept of fairness. My premise is that the way we think about fairness, and not any specific result of our thinking, is a root cause of many of the undesirable aspects of our modern process of litigation. Our narrow emphasis on perfecting re-

$\dagger$ U.S. Circuit Judge, U.S. Court of Appeals for the Second Circuit. This Comment was originally presented in somewhat different form as the Benjamin N. Cardozo Lecture of the Association of the Bar of the City of New York on November 8, 1984, and printed in The Record, Jan.-Feb. 1985 at 12. 
sults in the case at hand stems directly from our narrow perception of fairness. A broadened concept of fairness-one that includes fairness not only toward litigants in an individual case but also to all who use or wish to use the litigation system and to all who are affected by it-man lead to changes that directly confront the challenges of delay and expense. Rethinking the concept of fairness can produce a litigation system that broadly achieves fairness.

\section{Defects in the Litigation Process and the Difficulty of Making Ghanges}

The common perception that the litigation process is marred by undue delays and costs is correct. The list of those who suffer from the system's inadequacies most obviously includes the litigants who wait years for their day in court. It also includes the unwilling participants in the system-jurors who wait for hours that turn into weeks, witnesses who give up days of work to testify to facts of slight dispute and often less relevance, business executives who endure days of deposition questioning that yield little to the resolution of disputes in some of which their companies are not even involved. Perhaps the major impact is on the citizenry in general, whose attitude toward law and the legal system cannot help but be profoundly and negatively influenced by a litigation system that voraciously consumes time and money.

I recognize that there is a lively and increasingly informed debate as to the appropriate dimensions of our litigation system. Though the popular position has been to decry the amount of litigation and the time and expense needed to handle it, strong voices have been raised to assert that our litigiousness as a society is over-advertised. These voices contend that we submit fewer matters to court than we did at an earlier time and fewer than citizens of other countries. Emphasizing the virtues of litigation, they urge us to facilitate the resolution in court of more disputes to bring the promise of justice closer to reality. ${ }^{1}$

It is not my purpose to assess the quantity of our litigation. The object of my inquiry is the way we structure our litigation system, not its size. Whether we have too many cases or too few, or even, miraculously, precisely the right number, there can be little doubt that the system is not working very well. Too many cases take too much time to be resolved and impose too much cost upon litigants and taxpayers alike. No one should

1. See, e.g., Edwards, The Rising Work Load and Perceived "Bureaucracy" of the Federal Courts: A Causation-Based Approach to the Search for Appropriate Remedies, 68 Iowa L. REv. 871, 896-927 (1983); Galanter, Reading the Landscape of Disputes: What We Know and Don't Know (And Think We Know) About Our Allegedly Contentious and Litigious Society, 31 UCLA L. REV. 4 (1983). 
have to wait five years for a case to come to trial, but many litigants in this country face this reality. ${ }^{2}$ Legal expenses should not exceed damage awards, yet in the asbestos litigation morass, for example, those expenses total $\$ 1.56$ for every $\$ 1$ provided to a victim. ${ }^{3}$ If long delays and high litigation costs were aberrational, systemic change could safely be avoided. But we know the problem is more serious. Even if the modern defenders of our current litigation level are right, systemwide averages should not obscure the long delays and high costs imposed upon hundreds of thousands who use or participate in the litigation process and the losses endured by those who are deterred from seeking redress in court.

Proposals to reduce delays and costs are generally of three types. Some say we should provide more resources. More courts with more judges and more court personnel will enable the litigation system to keep pace with the growth in both population and the legitimate demands to resolve additional categories of disputes by the judicial process. Others point us in the opposite direction. They urge us to reduce the volume of cases permitted to enter the court system. There are two routes to that objective, each with costs not always acknowledged. The number of court cases can be reduced either by decreeing that some disputes are no longer to be adjudicated anywhere, with losses lying where they fall, or by devising alternative mechanisms for dispute resolution such as arbitration or mediation. Alternative mechanisms, of course, do not reduce volume; they only rechannel it, and the new channels will increasingly claim more resources and develop their own delays and expenses. The third broad approach is to alter the way we litigate, to make changes in both the substantive and the procedural law so that a dispute may still be brought into a court but resolved more quickly and less expensively.

As our litigation system has evolved, we have pursued all three courses in varying degrees. We have added judges. We have withdrawn categories of disputes by abolishing causes of action and by diverting cases to less formal forums. In the hope of saving time and money, we have amended our substantive and procedural law. Yet for all our efforts, the litigation system retains its flaws. ${ }^{4}$

2. Grossman, Kritzer, Bumiller \& McDougal, Measuring the Pace of Civil Litigation in Federal and State Trial Courts, 65 Judicature 86, 96 (1981).

3. Calculation derived from figures published by the Rand Institute for Civil Justice. See J. Kakalik, P. Ebener, W. Felstiner, G. Haggstrom \& M. Shanley, Variation in Asbestos Litigation Compensation and Expenses 89, Table 9.3 (1984).

4. Concern about the shortcomings of our litigation process is not a recent phenomenon; Roscoe Pound, for example, called the problem to our attention in 1906. See Pound, The Causes of Popular Dissatisfaction with the Administration of Justice, 40 AM. L. REv. 729 (1906), reprinted in 35 F.R.D. 273 (1964). The example of Pound offers a striking illustration of the gap between calling attention to a problem and achieving a remedy: His original concerns were echoed seventy years later at the Pound Conference. See Addresses Delivered at the National Conference on the Causes of 
Why is it that the earnest efforts of so many well-intentioned reformers yield such minor alterations? There are several answers plainly in view. One is the institutional resistance to fundamental change. Most institutions are inhospitable to change, and the institutions of the law are especially so. Since so much of law serves to maintain the strength of established arrangements, it is not surprising that the institutions of law tend to resist innovation, and that the key figures in these institutions fear the uncertain outcomes that bold changes might bring. In addition, the litigation system is primarily in the hands of judges and lawyers, whose professional training has made them experts in minutiae, but left them woefully ill-equipped to contemplate and implement institutional change. The inherent complexity of the litigation system tends to make the system resistant to the influence of outsiders. Nonlawyers, no matter how wellinformed, find it difficult to penetrate the intricacies of the system, and those who try are frequently rebuffed and reproached by the high priests of the law. "That's an interesting idea," they are told, "but, of course, it will not work for reasons too complicated for you to appreciate." And then, alas, there is the obstacle of pure greed. High litigation costs are fees to the clients, but they are income to the lawyers. Delays benefit at least one side in every litigation and sometimes both. Those who profit from the present system are unlikely to lead the assault on the citadel.

\section{The Role of Fairness and the Need for New Perspectives}

There is another, more fundamental explanation for the timeconsuming and expensive nature of our litigation system: the centrality of fairness as our governing standard. Fairness is the fundamental concept that guides our thinking about substantive and procedural law. Fairness provides the measure by which we gauge the virtues of familiar arrangements and the risks of innovation. We strive continually to reach the fair outcome, by which we usually mean our best approximation of the correct outcome-the one in which the facts have been correctly found and the law correctly applied. We strive to provide each side with a fair opportunity to achieve that outcome, by which we mean the chance to initiate and pursue any plausible claim or defense, the availability of elaborate means for producing and testing evidence, and the assurance of appellate review to enforce the rules of the present system. All of this we do in the name of fairness.

And so we should! It is assuredly not my purpose to suggest that we should shift our sights toward unfairness. But it is my contention that our efforts to reform the litigation process will rarely yield more than spo-

Popular Dissatisfaction with the Administration of Justice, 70 F.R.D. 79 (1976). 
radic, limited, and transient success until we change to some extent the way we think about that fundamental concept of fairness. The rethinking I have in mind concerns perspective. As lawyers we think about fairness in narrow terms. We need to broaden our perspective in three ways. First, we must learn to evaluate the fairness of each step in the litigation process not only in the narrow context of its own discrete contribution to the result, but in the broader context of its incremental value in promoting fairness compared to the inevitable risks of an unfair outcome. Second, we must include in our assessment of fairness not only fairness of result in the dispute at hand, but fairness in the broader context for all who use and wish to use the litigation process. Third, we must think about fairness of result not only in the familiar context of losses compensable within the legal framework, but in the broader context of all similar losses that occur across the whole spectrum of human activity.

\section{A. The Perspective of Trial Fallibility}

As lawyers we are trained to focus intently on precise facts and precise issues. We tend to think about one thing at a time. Professor Thomas Reed Powell is believed to have said: "If you can think about one thing that is inextricably related to another thing without thinking about the thing to which it is related, you will have learned to think like a lawyer." An elegant conception, to be sure, and a skill well learned by the best of our craft! Such narrow thinking usefully promotes habits of careful analysis, but it is a distinct handicap for making value judgments about the intrinsic worth of each item being examined. When we think about the fairness of each step in the litigation process, such narrow thinking is a substantial barrier to reform.

Whenever we consider procedural rules, we tend to think only of their supposed virtue in helping to achieve a fair result. We have a conception of attainable fairness, and so we are persuaded to accept all sorts of devices that hold any prospect of enhancing the likelihood of a fair outcome. I will assume for the moment that our procedures promote fairness or at least tend to do so. But their true worth cannot be soundly assessed unless we acknowledge the inherent limitations on our ability to achieve fairness in the course of litigation. That process is largely an exercise in determining facts, and the blunt reality is that our ability to tell where the truth resides in any disputed matter is always limited. Versions of the truth come from witnesses who err in their perceptions. Even what they perceive correctly, they sometimes fail to remember accurately. What they remember accurately, they sometimes are unable to report clearly. What they are capable of reporting clearly is sometimes tinged with subtle bias or wholly distorted by deliberate perjury. When accurate testimony is 
presented, it is sometimes misperceived by juries and judges. Finally, even the most conscientious juries and judges, hearing and perceiving the most fairly presented versions of the facts, will on occasion reach the wrong conclusions. Anyone who has had to choose between two conflicting versions of the facts will admit, at least to himself, that sometimes he had no sound basis for deciding whom to believe. Trials are not clinical investigations, performed under laboratory conditions. They are human confrontations, subject to all the normal risks of human error and with the risks compounded by the dramatic intensity of the event, the contentiousness of the adversary process, and the distortions that sometimes arise from disparity in talent and resources of the contending sides.

I point out these shortcomings not in despair. The courtroom trial is a marvelous invention, yielding in most instances a useful approximation of the truth and adjusting disputes peacefully and with a vital aura of legitimacy. But its fallibility is inevitable, and we ought to have that fallibility in mind when we decide what facets of the trial process are needed to achieve the degree of fairness we want.

The risk of fallibility can lead us in either of two opposite directions. We could say, as do many in our profession, that the risks of fallibility should make us more determined than ever to insist upon the most meticulous trial procedures, especially those designed to guard against the very factors that contribute to the risk of unfair outcomes. It is a powerful argument, and it ought to carry the day for some procedures, regardless of their time and cost. But the opposite argument deserves our attention as well. Since the trial outcome will not always be fair, we need not insist upon time-consuming and costly procedures simply because they offer some slight chance of promoting fairness, especially when the virtue of the procedure is a matter of faith and not demonstration. If we are trying to determine the depth of the snowfall in our backyard, it makes sense to use a yardstick, even though our measurement might be distorted because the wind might have blown some extra snow to the spot we measured or blown a little away. But it would not make sense to purchase an elaborate device to count the snowflakes. Too often when we think about achieving fairness through procedural devices, we are counting the snowflakes-refining our practices in an endeavor that at best can only approximate the ultimate determinations we wish to make.

Of course, the risk of error in fact-finding is more than the risk of missing the right answer by a slight degree; in some cases the risk is reaching the absolutely wrong answer. The person who should win something may receive nothing; the person who deserves nothing may receive something; the innocent person may be convicted; the guilty person may go free. Of all these risks, the one we properly strive the hardest to avoid 
is the risk of convicting the innocent. Yet even in guarding against this most dreadful prospect, we ought to assess the worth of our procedures in the context of trial fallibility. The celebrated collections of cases where the innocent were convicted are not filled with examples of failure to comply with elaborate procedures. The innocent are convicted primarily because eyewitnesses were mistaken. Some are convicted because a key witness deliberately lied. A few are convicted because incriminating circumstances led to a conclusion about the defendant's knowledge or intent that was simply incorrect. ${ }^{5}$ Our procedures offer very little prospect of diminishing these risks. That does not mean the procedures are without merit in criminal and civil trials. They play some part in minimizing some risks of error. My point is simply that an assessment of their worth-their real contribution to fairness-ought to be made in the context of the inevitable and significant causes of trial fallibility.

\section{B. The Perspective of System Fairness}

A second critical flaw in the way we think about fairness is that, although we scrupulously strive to achieve a fair outcome in the individual dispute, we rarely consider how to be fair to all who use or would like to use the litigation system. Not only do we focus on fairness of result, we assess procedural devices only for their tendency to affect the result, with little or no inquiry as to their incremental benefit. Even when we come to some considered assessment that a procedural device provides a significant benefit, we do not pursue the more searching inquiry into whether the benefit to be achieved in promoting fairness of result is worth the loss of system fairness, with its attendant social cost upon all who use or would like to use the litigation system.

It is not that we fail to understand the elements of cost-benefit analysis. When the issue is the worth of some rule that promotes important values at the risk of impairing others, we normally recognize the need to make an assessment of the overall impact of the rule. The exclusionary rule is defended by those who believe that its deterrent effect on police misconduct outweighs the significance of some number of unprosecuted crimes; ${ }^{6}$ it is opposed by those who weigh the competing concerns differently. ${ }^{7} \mathrm{Al}$ though both sides have scant basis for measuring either the deterrence the

5. Professor Borchard's well-known collection of 65 trials that convicted an innocent person illustrates the point that erroneous convictions are usually produced by erroneous testimony. In these trials, an eyewitness was honestly mistaken in 35 instances, and a key witness deliberately lied in 19 cases. See E. Borchard, Convicting the Innocent: Errors of Criminal Justice xiii, xxv (1932).

6. See, e.g., United States v. Leon, 104 S. Ct. 3405, 3437, 3443-44 \& nn.13, 14 (1984) (Brennan, J., dissenting).

7. See, e.g., Stone v. Powell, 428 U.S. 465, 498-500 (1976) (Burger, C.J., concurring). 
rule achieves or the extent of crime it tolerates, ${ }^{8}$ they at least purport to make the balance. With procedural steps that affect the time and cost of the litigation process, however, we not only make little effort to quantify the benefits, we too often fail to recognize the need to balance the benefits for particular outcomes and the social costs for the system as a whole. Fairness of result monopolizes our attention.

Once again, the narrowness of our thinking stems from the nature of our legal training. As lawyers we are taught to consider the dispute at hand and not the operation of the legal system in which the dispute arises and is resolved. Legal training from the first day in law school throughout a lawyer's career focuses on discrete controversies. We learn the facts of a particular case. We learn the principles applicable to a particular set of facts. We analyze the merits of a particular result. We examine the reasoning in a particular opinion. But always our focus is on a dispute and not on the consequences for the litigation process.

Furthermore, our training in the law rarely includes exposure to the rudimentary measurement arts of the social sciences. The rewards of practice and too often of the academy are bestowed almost exclusively on those who excel in the traditional fields of legal inquiry. There is an army of litigators for every trained legal administrator. There is a battalion of constitutional scholars for every serious student of the litigation system. Although we were all taught the intricacies of civil procedure, we seldom examined the volume of litigation, its social cost, or the techniques for examining the litigation process and determining the effects of change.

My concern is not with the pros and cons of any particular procedural devices, but with the way we think about their virtue. Nevertheless, a few aspects of procedure are worth mentioning, not to demonstrate that they are dispensable, but simply to invite thinking about them in a different light-thinking about the fairness they achieve, first, in the context of the inevitable fallibility of the trial process, and second, in the context of the operation of the litigation system as a whole. ${ }^{\ominus}$

I doubt that we should retain our current rule that a pleading should remain in court if any conceivable set of facts might support its allegations. We need not return to the days of Chitty's pleadings, but we could insist that complaints contain assertions of the essential facts. When the claim survives dismissal, I doubt that discovery should be routinely per-

8. See Oaks, Studying the Exclusionary Rule in Search and Seizure, 37 U. Crr. L. Rev. 665, 709 (1970) (noting absence of "empirical substantiation or refutation of the deterrent effect of the exclusionary rule").

9. For a recent analysis of the litigation system that calls for systemic reform but that does not consider the fairness question, see Miller, The Adversary System: Dinosaur or Phoenix, 69 MiNN. L. REV. 1 (1984). 
mitted. ${ }^{10}$ Where discovery is needed, I doubt that depositions should be permitted beyond two or three, limited to one hour, that interrogatories should be permitted beyond five or ten, and that any but precisely identified documents need be searched for and produced. Once discovery is complete, I doubt that we should confine the use of summary judgments as rigidly as we now do. In a case that proceeds to trial, I doubt that jury selection should be the elaborate process it is in most state courts. I doubt that witnesses must always be examined through question and answer techniques; a narrative would often be more informative, more readily understood, and quicker. I doubt that trial witnesses are needed at all in some cases; juries could decide some disputes simply from the contending claims of the lawyers, as in the non-binding summary trials now being experimented with in the Northern District of Ohio. ${ }^{11}$ Once a verdict has been reached, I doubt that appeals as of right must be available in all civil cases. Indeed, I doubt that the adversary process itself needs to be used uniformly across the entire spectrum of civil litigation.

There are risks in all of these suggestions. A conclusory complaint, if allowed to remain in court, might prevail upon full discovery and trial. One document disclosed in a search of scores of filing cabinets may be important. For lack of one more deposition, a witness might not be effectively cross-examined. A case rejected on summary judgment might, upon trial, prove successful. A venireman not subjected to elaborate voir dire might enter the jury box with insurmountable bias. Narrative testimony might include impermissible facts. Live testimony might be decisive. An appeal might result in a retrial with a different outcome. Of course, these possibilities exist. Our litigation procedures are not vulnerable because they are useless; they deserve reexamination because they may not be worth having.

In many cases, the lack of these additional safeguards will not affect the result. The extra document may have no real bearing on an outcome determined by all the vagaries and occasional venalities of witnesses. The impermissible fact mentioned in narrative testimony may be lost in the welter of pertinent information. Some procedural protections may even be detrimental to a fair result. The time spent to interrogate potential jurors may weed out the conscientious ones who admit to bias and would strive mightily to lay it aside, but send into the jury box the artful perjurers whose biases were undetected by the amateur psychoanalysis we call voir dire.

But what of the instances when abandoning or revising a procedure

10. For a more detailed reexamination of current discovery practices, see id. at 22-24.

11. For a discussion of the procedures used in these trials, see Lambros \& Shunk, The Summary Jury Trial, 29 Cleve. ST. L. REv. 43 (1980). 
would alter the outcome? If our focus is only on fairness of outcome, the inquiry is easy. We retain any procedure that could conceivably increase the likelihood of obtaining a fair result. That principle has been the foundation on which we have built the present structure of our litigation system. But if our sense of fairness extends beyond the outcome, then additional analysis is necessary. We should not, for example, retain extensive jury voir dire simply because many lawyers are convinced that it has some benefit in promoting fairness of outcome in their cases. We must first make some serious assessment of its real worth in ferreting out bias. We must then determine whether that incremental benefit to the litigants in each case justifies the delays and consequent loss of fairness to all others affected by the litigation process-including those incarcerated in pretrial detention awaiting their chance to have a trial.

Fairness of system is not some abstraction competing against the flesh and blood claims of fairness of outcome. Fairness of system reflects the aggregate impact of the litigation process upon the lives of all actual and potential litigants. It is concerned with the money each person is obliged to spend to achieve an outcome, with the time each person must invest until an outcome is reached, and with losses uncompensated because the litigation process is rightly perceived as involving too much time and money to justify its use.

\section{The Perspective of Those with Losses Outside the System of Legal Liability}

A third deficiency in the way we think about fairness is our tendency to consider fairness solely in the context of matters amenable to litigation instead of in the broader context of similar events of the real world. This aspect of thinking about fairness implicates substantive standards, rather than procedural devices. Some substantive standards seem eminently fair when viewed within the context of the litigation process. Though we recognize that it takes time and money to determine whether a given legal standard has been met, we instinctively conclude that the benefit is worth the costs because we are looking at the standard as it applies only to those within the framework of actual or potential litigation. But if we look beyond that framework, the intrinsic fairness of some standards might seem less compelling and their benefits might not always seem worth the social costs of the litigation.

Let me explore an example from the field of compensation for injury. When lawyers think about the operation of our system for compensating injuries, they tend to think only about those misfortunes compensable according to the rules of law-primarily the rules of tort liability. The very topic conjures up images of the accident victim. Because we are used to 
the substantive rules of liability, we assume that the victim who suffers physical impairment should receive a significant sum of money to compensate for various consequences of injury. A victim should receive money for medical costs, for lost wages, for the fact of disability, and for pain and suffering. I distinguish the fact of disability from pain and suffering for reasons that will shortly become apparent. ${ }^{12}$ Even to suggest that some of these elements are inappropriate for compensation is to venture onto heretical ground. But if disbelief might be suspended for just a moment, the process of reexamination could begin by first broadening the context in which the appropriateness of compensation is to be assessed.

Suppose we broaden the context to include not just those whose impairments stem from tortious wrongs but all persons who have physical impairments regardless of the cause of their disability. We include those injured by their own carelessness, those accidentally injured through no one's fault, those whose impairments stem from birth defects or disease or war. In that universe of persons, each with an equivalent degree of serious physical impairment, what is an appropriate measure of compensation? As a general matter, our society has agreed to pay a portion of a person's medical expenses if he is poor or elderly. ${ }^{13}$ If the impairment is so serious that the person is totally incapable of work, we are also willing to provide some wage earners with a modest disability payment, ${ }^{14}$ compensating for a portion of lost wages and perhaps, to a very limited extent, for the fact of disability. If the disability arises from military service, even if the person is not totally disabled, we provide medical care and a scheduled level of disability payments. ${ }^{15}$ And as to those in this broader universe, whether or not eligible for medical or disability benefits, what compensation do we afford for their pain and suffering? The answer of course is none. Yet if pain and suffering are fit subjects for compensation, how can we so blithely fail to compensate the pain and suffering of millions who have the double misfortune of a serious physical impairment and no basis for a lawsuit that falls within traditional notions of legal liability?

12. Though courts sometimes speak of pain and suffering damages as including disability, e.g., Gretchen v. United States, 618 F.2d 177, 180 (2d Cir. 1980), the distinction between an award for pain and suffering and an award for the fact of disability has been recognized in cases that distinguish between pain and suffering and impairment of enjoyment of life, e.g., Petition for U.S. Steel Corp., 436 F.2d 1256, 1265-67 (6th Cir. 1970), cert. denied, 402 U.S. 987 (1971), or between pain and suffering and permanent injuries, e.g., Traylor v. United States, 396 F.2d 837, 839-40 (6th Cir. 1968). Juries are frequently instructed to consider damages both for an injury and for pain and suffering. See, e.g., NEw YORK PATTERN JURY INSTRuCtTons -Crvil 2:280 (1974) (allowing jury to make an award for "injury" and for "conscious pain and suffering"); id. at 2:280A (Supp. 1984) (authorizing award "for the injury and for the conscious pain and suffering caused by the injury").

13. See 42 U.S.C. $\$ \S 1395-1396$ p (1982) (federal health insurance for aged and disabled).

14. See id. $\S 423$ (federal disability insurance benefits).

15. See 38 U.S.C. $\$ \S 314,610$ (1982) (federal health care and disability compensation for veterans injured in line of duty). 
No doubt it seems bizarre even to suggest that all those with serious impairments that cause them to endure pain and suffering ought to receive some compensation on that account. I am not urging that their pain and suffering should be compensated. On the contrary, I raise the point only to provide a perspective on the correlative suggestion I do make, namely, that pain and suffering arising within the traditional context of tort liability should not be compensated. I make this suggestion as an example of the type of fundamental rethinking that $I$ believe is necessary. The pertinence of this example stems from the effect of pain and suffering damages on the frequency of jury trials.

I strongly suspect that, of all the compensable elements of traditional torts, the element of pain and suffering is often the most significant determinant of whether a negligence case will be settled or tried. Even if unsure of what the jury will do in a particular case, lawyers are frequently in remarkable agreement in estimating the probability of a plaintiff's verdict on liability and hence in providing a mathematical basis for determining a fair settlement once the likely damage award has been fairly estimated. When they turn to that likely award, they can reach agreement fairly easily on medical costs already incurred and even on a reasonable estimate of future medical expenses. Past wages are rarely in dispute. Future wages are sometimes in dispute, but few settlement negotiations break down on that point. Lawyers frequently agree even upon the likely award for a disability. What propels many litigants past the settlement table and into the courtroom is the high stakes game of pain and suffering damages. To be sure, uncertainty as to whether the jury will award five thousand or five hundred thousand sometimes promotes a settlement because neither side wants to take the chance that its worst fears will be realized. But in other cases the parties go to trial because they have determined that the risk of a disappointingly low (or high) award of pain and suffering damages is worth the chance of obtaining a successful outcome.

If only their time and money were at stake, the choice should be theirs. But if it could be demonstrated, as I suspect, that the availability of pain and suffering damages induces litigants in a significant number of instances to try a case they would otherwise settle, then the burdens on the litigation process must be carefully assessed and balanced against the interests of individual plaintiffs. That balancing will be incomplete if all we think about is the traditional entitlement of tort victims to damages for pain and suffering. But if we expand the context and think about all who suffer similar misfortune, we may begin to wonder whether a payment for pain and suffering, which goes only to tort victims, is really as fair as we have always assumed. At least if we think about all those with a similar impairment, we will make a more dispassionate assessment of the worth 
of pain and suffering damages. We will then be in a position to judge whether fairness requires this component of a tort recovery at all or perhaps only up to some specified limit, ${ }^{16}$ and whether it makes sense to impose on our litigation system the costs of deciding which plaintiffs should receive such damages and in what amounts.

We should also take a hard look at lost future income. In the context of tort litigation, we assume that it is only fair to give the injured executive full compensation for the loss of his high salary, while awarding the injured tradesman only his more modest lost wages. But the executive would have been just as deprived of his income if the cause of his disabling injury had not been a negligent, fully-insured motorist, but instead a fall in his own bathtub or a crippling disease. We might not think that fairness requires an award of all lost income for the injured executive if we thought about him in the context of all persons with a similar impairment. And we might well conclude that a ceiling on recoverable future wages would be appropriate in all tort cases if it were shown to reduce the number of trials. Similar considerations might justify scheduled awards for the fact of disability, or at least ceilings on this component of damages.

Of course, more is at stake in assessing the components of tort recovery than fairness to the injured person and burdens upon the litigation process. The elements of a damage award may play some part in the deterrent effect of tort law, especially in products liability. But in many contexts deterrence is unlikely. I doubt, for example, that many motorists take an extra measure of care because the damages a jury is permitted to award the victim of their negligence can include a generous sum for pain and suffering. Even where the possibility of deterrence is realistic, it should not automatically outweigh other considerations. We should not impose heavy burdens on our litigation system without some basis for estimating whether these burdens are justified by whatever reduction in accidents results from the prospect of high damage awards.

Once we begin to think about fairness to those who suffer losses not in narrow terms of losses traditionally compensable in lawsuits, but of similar losses suffered by all, our thinking about the litigation process will

16. There is precedent for limiting pain and suffering damages. In 1972, New Zealand, as part of a comprehensive reform of its accident compensation scheme, limited such damages to $\$ 7500$ in New Zealand currency. See Accident Compensation Act 1972, [1972] N.Z. Stat. No. 43, § 120. The limit was subsequently raised to $\$ 10,000$. See Accident Compensation Act 1982, [1982] N.Z. Stat. No. 181, $\S 79$. For a commentary on the pain and suffering provisions of the original act, see $T$. Ison, Accident Compensation: A Commentary on the New Zealand Scheme 64-68 (1980). Similarly, in malpractice cases, California has statutorily limited pain and suffering awards to $\$ 250,000$. See Medical Injury Compensation Reform Act of 1975, CAL. Crv. CoDE $\S 3333.2$ (West 1985). The California Supreme Court recently upheld the constitutionality of this measure. See Fein v. Permanente Medical Group, 38 Cal. 3d 137, 695 P.2d 665, 211 Cal. Rptr. 368 (1985). 
produce significant changes. We may decide that certain losses or components of losses that we now assume must be the subject of litigation can be removed from litigation entirely. In some instances, the losses would simply lie where they fall, with the option of private insurance available. Alternatively, compensation for loss could be provided by social insurance at modest, scheduled levels of recovery. ${ }^{17}$ Even if existing grounds of liability are not altered, we might consider placing ceilings on damages, ceilings that we candidly recognize would provide substantially less than the full recovery we have traditionally assumed should be awarded. We might also want to take a hard look at treble damages in antitrust law and punitive damages in general. What are the benefits of these recoveries and how many unnecessary trials do they stimulate? Limited awards might achieve sufficient benefits with fewer burdens.

My primary concern is not to argue the case for particular changes such as limiting pretrial discovery or eliminating damages for pain and suffering. Indeed, debate over any one change may too easily obscure my underlying point. My concern throughout is not what we should do about our procedural and substantive rules, but the way we should think about them, particularly the way we might think about the fairness they are designed to achieve.

\section{A Limited Judicial Role}

The rethinking I have suggested might profitably be undertaken by all concerned with the litigation system, legislators and judges, practitioners and academics. All contribute to the nature of the litigation process, and all have a significant role in diagnosing our current problems and formulating and reacting to proposals for change. Whether the ultimate implementation of change is more in the domain of the legislator or the judge, however, is another matter. For most changes, revision achieved by rule will be preferable to revision accomplished in the resolution of a particular lawsuit. Most basic standards ought to emanate from legislators, though rulemaking by judges sometimes plays a useful role. Revision accomplished in the decision of a case ought to occur infrequently. But changes that vitally affect the litigation system have been made in individual decisions and can legitimately be revised in the same way. It was the Supreme Court's decison in Conley v. Gibson ${ }^{18}$ that authoritatively committed us to the proposition that a complaint must remain in court if any

17. We have already begun to venture into this mode of thinking: Through workers' compensation we have altered the traditional standards of tort recovery for those injured at the workplace, providing certainty of recovery in exchange for limits on the amount of recovery. Other losses are amenable to similar arrangements.

18. 355 U.S. $41,45-46$ (1957). 
set of facts can conceivably be imagined that might support its allegations. It would be entirely within the judicial function for a subsequent decision to make some adjustment in that doctrine. ${ }^{19}$

The legitimate role of the judge in permitting considerations of fairness throughout the litigation system to influence the outcome of the case at hand was brought sharply into focus recently in a case from the Southern District of New York that found its way to the Second Circuit. In Mallis v. Bankers Trust Co. ${ }^{20}$ Judge Carter was asked to set aside a plaintiff's verdict and order a new trial on the ground that the verdict was against the weight of the evidence. Through no fault of the defendant, the case had been tried twice and was then seven years old. Judge Carter candidly acknowledged that the time and cost already devoted to the litigation was a substantial and perhaps decisive factor in his discretionary decision to deny the motion. ${ }^{21}$ On appeal Judge Lumbard, expressed the view of the panel that "the passage of time, by itself, is a consideration which should not have been given any weight in denying the new trial motion."22 I disagreed and endeavored to explain why, at least on a discretionary ruling such as this, the trial judge was entitled to weigh the time and resources already devoted to the case. ${ }^{23}$ Interestingly, the panel unanimously affirmed the plaintiff's judgment, perhaps indicating that all of us in some fashion shared Judge Carter's view that a third trial would have been an unwarranted burden on the court system. Whether or not my view of the matter was sound, the case illustrates that concerns about the time litigation takes are not likely at present to receive explicit approval as the basis for decision of specific cases.

The views of the majority in Mallis are entirely understandable. They reflect a natural aversion to what may seem to be no more than arguments of expediency. They also reflect, I suspect, a tacit acceptance of the present state of our litigation system, or at least a view, common throughout the judiciary, that with the system already overloaded with so many cases, the additional time to try one more case, or to accord one more procedural step to one more litigant, will add only a drop of water to the flood. I urge the opposing point of view because I believe that what is at stake is far more than a matter of expediency. We must think hard about ways to save time and money in the litigation system so that the system can func-

19. Judges of the lower federal courts have already made some selective inroads on the doctrine. They have, for example, required substantial fact pleading in complaints alleging civil rights conspiracies. E.g., Blackburn v. Fisk Univ., 443 F.2d 121 (6th Cir. 1971); Powell v. Workmen's Compensation Bd., 327 F.2d 131 (2d Cir. 1964).

20. 717 F.2d 683 (2d Cir. 1983).

21. See id. at 696 (Newman, J., concurring) (discussing lower court opinion).

22. Id. at 692 (Lumbard, J.).

23. Id. at 695-700 (Newman, J., concurring). 
tion properly and thereby provide justice for all who wish to use it or are affected by it. We need to rethink our conception of fairness not simply to save time and money but to distribute fairness more evenly. In this regard, each of us might find it useful to follow the approach of John Rawls and consider, from behind "the veil of ignorance," 24 what type of a litigation system we would prefer to have if we did not know what our role in the system might be-whether litigant, witness, juror, lawyer, judge, or citizen. A view of the litigation system from that disinterested perspective would yield fresh insights into what we mean and ought to mean by fairness.

\section{Prerequisites for Change}

Once we are willing to rethink the concept of fairness, three things must be done to enhance the likelihood of bold changes in the procedure and substance of litigation. First, we must vastly expand our efforts to gather the empirical data necessary for sound evaluations of the real worth of each component of our litigation system and for hard calculations of the burdens upon the entire system. Thus far we have made only the most rudimentary attempts to assess the value of what we do in the litigation process. We operate primarily by intuition, reenforced by the comfort of tradition. We need to know, for example, what degree of benefit is provided by extended voir dire examination of jurors and at what cost. We need to have a sense of how many complaints would be dismissed at the threshold if some degree of fact pleading were generally required and how many of these complaints would ultimately have been meritorious if not dismissed. We need to know how many trials are precipitated by the prospect of pain and suffering damages and what results would be achieved by substituting partially compensatory alternative arrangements.

In all areas of social endeavor, specific proposals for change are inadequately subjected to quantitative assessment. The litigation system is not unique in the paucity of available pertinent data. We have learned to count the cases, but we have wholly inadequate data for determining the worth and cost of each step in the litigation process. Although personal judgments will always play a part in even the most sophisticated of empirical evaluations, we need not rely solely on intuition and habit. Surely we can do better in finding out the value and the cost of what we are doing in our courtrooms.

Second, as our empirical data are assembled, we will need to take the further step of experimenting with changes. As law has been in the main inhospitable to change, it has been especially leery of experimentation.

24. J. Rawls, A Theory of Justice 136 (1971). 
For those trained in the law, uniformity of procedure is a watchword, reenforced by ethical concerns and by the values, if not requirements, of the Equal Protection Clause. The appropriate bounds of experimentation in the law is a topic unto itself. ${ }^{25}$ Without essaying the complexities, I simply note the irony that the medical profession has made enormous progress by experimenting with matters of life and death, while we in the law shun experimental ways of deciding matters of property.

Third, I suggest that fundamental rethinking about the nature of fairness in our litigation system will not progress very far until legal education decides to place these issues in the curriculum and to recognize them as subjects of serious scholarship. The next generation of lawyers will determine how profoundly we deal with the burdens of litigation. The law schools will determine whether that generation is interested in reform, creative in its thinking, and equipped to design and implement significant changes.

\section{CoNCLusion}

We need not wait for the combined effects of empirical research, experimentation, and academic attention to begin the reexamination of our legal process. Each of us has the capacity to rethink what our litigation system ought to be. The process of litigation is a product of the mind. Its improvement can emerge from creative thinking. The current condition of the litigation process demands that we think hard about the way we litigate and the matters worth litigating. Such thinking must include consideration of what we mean and ought to mean by "fairness," for our conception of fairness has significantly shaped our ideas about what should happen in our courtrooms. If we are to think anew about the litigation process, we must first be willing to rethink our conception of fairness. That task will be unsettling for some, but worthwhile for all.

25. See Fed. Judicial Genter Advisory Comm. on Experimentation in the Law, ExPERIMENTATION IN THE LAW (1981). 